
\title{
$\begin{array}{ll}\text { Research Square } & \begin{array}{l}\text { Preprints are preliminary reports that have not undergone peer review. } \\ \text { They should not be considered conclusive, used to inform clinical practice, } \\ \text { or referenced by the media as validated information. }\end{array}\end{array}$
}

\section{The Costs of Using Volunteers in a COVID-19 pandemic Response Program in Iran}

\section{Hamed Seddighi ( $\boldsymbol{Q}$ hseddighi@gmail.com )}

Student Research Committee, University of Social Welfare and Rehabilitation Sciences, Tehran, Iran https://orcid.org/0000-0002-6214-4830

\section{Ibrahim Salmani}

Department of Health in Disaster and Emergency, School of Public Health, Shahid Sadoughi University of Medical Sciences, Yazd, Iran

\section{Mehrab sharifi sedeh}

University of Medical Sciences, Yazd, Iran, e.salmani.n@gmail.com Mehrab sharifi sedeh: Department of Disaster Public Health, School of Public Health, Tehran University of Medical Science (TUMS), Iran

\section{Research Article}

Keywords: Benefit-Cost, Volunteering, COVID-19, Humanitarian emergency

Posted Date: July 20th, 2020

DOI: https://doi.org/10.21203/rs.3.rs-44019/v1

License: (c) (i) This work is licensed under a Creative Commons Attribution 4.0 International License. Read Full License 


\section{Abstract}

An intervention that Iran implemented to reduce the spread of the COVID-19 pandemic was to screen passengers during the Iranian New Year holidays (17 March to 3 April 2020). The purpose of this study is to examine the costs and benefits of using volunteers in this program for the Iranian government. Using the cost-benefit analysis method, the national data of the screening program were analyzed. A total of 83,810 volunteers worked on the project for 17 days, which cost $\$ 27,7811$. If the Iranian government had hired permanent employees instead of using volunteers, it would have cost $\$ 558733$ more. It is used wage replacement method for calculating cost of voluntary work using the minimum wage of workers in Iran in 2020. Volunteer Investment and Value Audit (VIVA) rate also showed that $\$ 2$ was saved for every dollar the Iranian government spent. It can be concluded that the use of volunteers, especially in volunteer-oriented programs in times of disaster, including epidemics, can be economically beneficial to the government. At the same time, it should be noted that the use of volunteers is also costly, and the government must identify the optimal number of volunteers before implementation. Moreover, if there are several plans on the table to intervene, the Viva rate can be a measure of cost-effectiveness.

\section{Introduction}

On 19 February 2020, Iran reported its first confirmed case of COVID-19 infection ${ }^{1}$. Iran is among the top ten countries in terms of people infected by COVID-19 in the world until April 16, 20202. The number of infected people and deaths are increasing still in May $2020^{2}$. It is confirmed 126964 cases in Iran and 7183 deaths from COVID-19 outbreak in Iran. It is shown the trend of death by COVID-19 outbreak in Iran in Figure 1.

Researchers began valuing off-market services for the first time in the 1920s and early 1930s by researching housekeeping services that the market has not priced ${ }^{3}$. In the following decades, the issue of the monetary value of public goods in general and the valuation of voluntary labor in particular was examined by various researchers in the field of economics and policy ${ }^{4}$. Cnaan et al. (1996) provided a framework for defining volunteers by reviewing more than three hundred different definitions of the term volunteer ${ }^{5}$. A person with his or her own will and without a salary - does work for a non-profit organization, and the members of the organization and other people are the beneficiaries of voluntary activities ${ }^{5}$. Numerous initiatives have been taken in recent decades to identify the importance and extent of volunteerism, such as the Johns Hopkins Economic Data Project, the Volunteer Assessment Project, and the United Nations Nonprofit Organization's Operation Book of Civil Society Studies at Johns Hopkins University ${ }^{6}$. Many stakeholders are interested in the economic value of volunteer work ${ }^{7}$. For example, social investors are interested in returning their capital. Lobbyists and nonprofits use economic valuation to show policymakers the importance of volunteering in society and the importance of volunteering. They are looking for government subsidies for the volunteer sector, and lawmakers want to know how useful 
the subsidies they approved and allocated have been. Economists are interested in knowing how important the volunteer section is compared to other sections. All stakeholders are more interested in knowing statistical information and monetary value of voluntary activities than in qualitative data ${ }^{8}$.

In Iran, various voluntary activities are carried out ${ }^{9,10}$. Due to the high number of disasters in Iran, volunteering is also popular in emergencies ${ }^{11}$. For example, the Iranian Red Crescent Society ranks second among the national Red Cross and Red Crescent societies in terms of the number of volunteers in the world ${ }^{12}$. This has led Iran to use its volunteers in emergencies including in COVID-19 response. Due to the increase in the number of people with corona and the increase in travel due to the new year in Iran, the Iranian government decided to set up screening stations at the entrances and exits of all cities ${ }^{2}$. In this plan, the Red Crescent operational volunteers, based on the situation in the 31 provinces, worked in more than 851 temporary posts at the entrances and exits of cities, train stations, and airports to control passengers and identify infected people to COVID-19².

However, the use of volunteers will incur costs and benefits for the country and volunteer organizations. Thus far, not much research has been done on the economic value of voluntary activities in Iran. This study aims to determine the economic cost of using volunteers in the Corona screening scheme, as well as its monetary benefits for the Iranian government.

\section{Methods}

It is used a benefit-cost analysis (BCA) method for this study ${ }^{13}$. BCA is a type of policy analysis method that evaluates the value of all impacts of a policy to all members of a community or a society in monetary terms. It is used this method for regulations, policies, programs, projects, and other interventions. This method helping to policy makers and authorities to improve efficiency ${ }^{13}$. BCA could be used before the intervention, or after the intervention that is called ex post or retrospective $B C A^{14}$. In the retrospective BCA, the question is: "was this policy or project a good idea?"

In this descriptive-analytical study, considering the expenditures and costs of the COVID-19 screening national plan of passengers. It is used wage replacement method for calculating the cost of voluntary work. The data from this method was obtained from daily reports from Red Crescent. The replacement wage approach directly assesses the activity that is performed in volunteering work ${ }^{15}$. In this approach is indicated the economic value of volunteers by calculating the hourly wage cost of doing the same work by the workforce ${ }^{16}$. The identification of wage and labor market costs will be possible, but the search for this cost and the amount is challenging and time consuming. Therefore, it is used the minimum salary of workers in Iran in 2020.

For calculation of volunteers, benefit for the government was used from the Volunteer Investment and Value Audit (VIVA) method. It is a method that analyzes the costs and activities associated with the volunteer program and compares it to work in the job market, and this ratio represents the amount of return on investments made related to the volunteers' program ${ }^{17}$. The allocation of market value or 
"shadow wage" represents the amount that the organization would have to pay to the workforce if it did not have voluntary workforce services. With the VIVA rate also it is possible to conduct a costeffectiveness analysis through input measurements (resources used to support the volunteer) relative to the output (the monetary value of the time spent by the volunteer) for different programs. This method also shows the organization's economic saves for each dollar spent ${ }^{18}$.

The VIVA (investment on volunteer and economic value of volunteering work) rate is calculated by the following formula ${ }^{17}$ :

VIVA $=\frac{\text { Economic value of volunteer }}{\text { The investment amount of volunteer (costs that have been done for volunteer ) }}$

\section{Results}

From March 18 to April 5, the project provided screening and metering services to 21,640,861 people. Based on the situation in the provinces, the Red Crescent volunteers worked on more than 851 temporary stations at the entrances and exits of cities, train stations, and airports to control passengers and identify infected people. Screening and fever monitoring were associated with symptoms of high fever. The number of volunteers for this project was 4,930 per day in the Red Crescent screening and metering posts in different provinces. In total, 95,371 people were used by the rescue forces to implement the national plan for screening and fever testing of their compatriots, using 15,278 vehicles per day.

According to the data presented in Table 1, the Yazd Red Crescent Population has spent \$ 6547.7 on young people volunteering for the National Safety and Health Plan of Nowruz Passengers

Table 1) Cost of the program

\begin{tabular}{|c|c|c|c|}
\hline Costs & Description & Number & $\begin{array}{l}\text { Spent cost } \\
\text { (dollar) }\end{array}$ \\
\hline Food & The minimum cost that is paid to a volunteer for a hot meal at each post is $\$ 1$ for each person. & 83810 & 83810 \\
\hline Transportation & $\begin{array}{l}\text { The minimum cost that is paid to travel to the post office or Red Crescent Branch is } \$ 1 \text { for each } \\
\text { person. }\end{array}$ & 83810 & 83810 \\
\hline $\begin{array}{l}\text { Equipment and } \\
\text { Supplies }\end{array}$ & $\begin{array}{l}\text { The equipment that had been necessary for the presence of a volunteer in a plan, such as an } \\
\text { identity cover and ... for each post is } \$ 31\end{array}$ & 851 & 26381 \\
\hline Training & The cost that has been spent for training volunteers at each post $1 \$$ & 83810 & 83810 \\
\hline \multicolumn{2}{|l|}{ Sum } & & 277811 \\
\hline
\end{tabular}


Volunteers did not receive a salary for their work in this project. If they were to be hired for the project, such as police officers or the Ministry of Health, they would have to be paid. The minimum wage for in Iran for workers is 28 million IR Rials or $\$ 200$ per month ( $\$ 6.6$ per day). On this account, the Iranian government had to pay a sum of 558733 .

$$
\operatorname{VIVA}=\frac{558733}{277811}=2.01
$$

\section{Discussion}

The findings of this study showed that volunteer work is a major economic source in Iran. The findings of previous studies also confirm this ${ }^{16,19,20}$. Using volunteers in emergency situations is usual in the world and many countries are investing in $\mathrm{it}^{21-25}$. For example, a study in Australia was showed that the Australian Government, spent 83 million in a year for volunteer's management for emergency management ${ }^{26}$. However, it should be noted that the benefits of volunteers in emergencies, because of their intangible character, cannot be monetized easily ${ }^{27-29}$.

The study also found that for every dollar the Iranian government spent on the project, it saved $\$ 2$. Another study in Iran found that using the volunteer force for the Iranian government saved more than \$ 4 per dollar ${ }^{30}$. The reason for the decrease in this rate in recent years is the devaluation of Iran's currency and the consequent rise in prices for various services such as food and transportation ${ }^{31}$. On the other hand, wages in Iran have not increased in proportion to the devaluation of the currency ${ }^{32}$. Thus, the VIVA rate has halved in five years. In other words, the cost of volunteer-oriented programs for humanitarian and government organizations has also increased. This suggests that these organizations need to analyze the benefit-cost analysis before starting the program. In addition, given the high costs such as food and transportation, humanitarian organizations and the government need to be careful in determining the optimal number of volunteers needed in humanitarian programs. Otherwise, they will have to pay a lot of money to pay for the logistics costs. The International Federation of Red Cross and Red Crescent Societies published various reports on the value of voluntary programs in different countries ${ }^{33}$. The reports were indicated that the VIVA rate for a voluntary preparedness Programme by the New Zealand Red Cross was 41; voluntary emergency response program by Pakistan Red Crescent was 3; and a youth engagement in family medicine kit project by China Red Cross was $11^{33}$.

Iran is in one of the worst economic conditions in recent years ${ }^{34}$. If the plan was to be carried out by another organization, such as the Police, Army, and the Ministry of Health with permanent employees, the government might not have been able to pay for its funding and would not have done so at all. Moreover, in this study, the alternative method of wage and including the minimum wage of workers in Iran was used. If instead of the minimum wage, the average wage of health workers was used, the cost of this plan would certainly be much higher. This study focused only on the economic benefits of this project, but the social benefits of this project are also very significant. The project helped identify people with the 
disease $^{2}$. It also sensitized the public to safety precautions to prevent the coronavirus ${ }^{2}$. The plan came as the government ordered a nationwide quarantine and did not intend to use military force to force people to stay home. Another goal of the project was to encourage people to stay home and not travel between cities $^{2}$. Because with the implementation of this plan, long queues were created at the entrances and exits of all cities in Iran. This caused the passengers to get tired and return to their hometown, as well as other people to stop traveling. Voluntary program has positive impacts on volunteers themselves, including skills, social relations, and wellbeing ${ }^{35-37}$. However, it is also possible to determine whether other projects can be done at a lower cost. Measuring passenger fever is not the most accurate way to detect coronavirus. That's why it can be useful to spend a lot of money on such projects.

\section{Conclusion}

Using the cost-benefit analysis method, the national data of the screening program were analyzed. A total of 83,810 volunteers worked on the project for 17 days, which cost $\$ 27,7811$. If the Iranian government had hired permanent employees instead of using volunteers, it would have cost $\$ 558733$ more. It is used wage replacement method for calculating the cost of voluntary work using the minimum wage of workers in Iran in 2020. Volunteer Investment and Value Audit (VIVA) rate also showed that $\$ 2$ was saved for every dollar the Iranian government spent. It can be concluded that the use of volunteers, especially in volunteer-oriented programs in times of disaster, including epidemics, can be economically beneficial to the government. At the same time, it should be noted that the use of volunteers is also costly, and the government must identify the optimal number of volunteers before implementation. Also, if there are several plans on the table to intervene, the Viva rate can be a measure of cost-effectiveness.

\section{Declarations}

\section{Ethics approval and consent to participate}

Not applicable.

\section{Consent for publication}

Not applicable.

\section{Competing interests}

The authors declare no competing interests.

\section{References}

1. Takian A, Raoofi A, Kazempour-Ardebili S. COVID-19 battle during the toughest sanctions against Iran. Lancet (London, England). 2020;395(10229):1035. 
2. Seddighi $\mathrm{H}$. The performance of the Iranian Red Crescent by launching COVID-19 Testing Centers: Report from the field. Disaster Medicine and Public Health Preparedness. 2020:1-6.

3. More-Hollerweger E, Bowman W, Gavurova B, Kuvikova H, Park T-k. Economics of associations and volunteering. The Palgrave Handbook of Volunteering, Civic Participation, and Nonprofit Associations: Springer; 2016:1074-1090.

4. Sardinha BMB. The economics of the volunteering decision. 2011.

5. Cnaan RA, Handy F, Wadsworth M. Defining who is a volunteer: Conceptual and empirical considerations. Nonprofit and voluntary sector quarterly. 1996;25(3):364-383.

6. Raposa EB, Dietz N, Rhodes JE. Trends in volunteer mentoring in the United States: Analysis of a decade of census survey data. American Journal of Community Psychology. 2017;59(1-2):3-14.

7. Brudney JL, Meijs LC, van Overbeeke PS. More is less? The volunteer stewardship framework and models. Nonprofit Management and Leadership. 2019;30(1):69-87.

8. Rochester C, Paine AE, Howlett S, Zimmeck M, Paine AE. Volunteering and Society in the 21st Century. Springer; 2016.

9. Alami A, Nedjat S, Majdzadeh R, Foroushani AR, Hoseini S, Malekafzali H. Factors influencing women's willingness to volunteer in the healthcare system: evidence from the Islamic Republic of Iran. 2013.

10. Bagheri M, Noughani F, Moltafet $\mathrm{H}$. Formation of Voluntary Associations in Iran. SOCIAL WORK. 2008;69(1).

11. Salmani I, Seyedin H, Ardalan A, Farajkhoda T. Conceptual model of managing health care volunteers in disasters: a mixed method study. BMC health services research. 2019;19(1):241.

12. IFRC. Everyone Counts. Geneva: International Federation of Red Cross and Red Crescent Societies; 20192019.

13. Boardman AE, Greenberg DH, Vining AR, Weimer DL. Cost-Benefit Analysis: Concepts and Practice. Cambridge University Press; 2017.

14. Florio M, Vignetti S. The use of ex post cost-benefit analysis to assess the long-term effects of major infrastructure projects. Available at SSRN 2723381. 2013.

15. Pho YH. The value of volunteer labor and the factors influencing participation: Evidence for the United States from 2002 through 2005. Review of Income and Wealth. 2008;54(2):220-236.

16. Bowman W. The economic value of volunteers to nonprofit organizations. Nonprofit Management and Leadership. 2009;19(4):491-506.

17. Handy F, Mook L. Volunteering and volunteers: Benefit-cost analyses. Research on Social Work Practice. 2011;21(4):412-420.

18. Handy F, Srinivasan N. Valuing volunteers: An economic evaluation of the net benefits of hospital volunteers. Nonprofit and Voluntary Sector Quarterly. 2004;33(1):28-54.

19. Cordery CJ, Proctor-Thomson SB, Smith KA. Towards communicating the value of volunteers: lessons from the field. Public Money \& Management. 2013;33(1):47-54. 
20. Tooley S, Hooks J. Accounting for Volunteers: Enhancing Organizational Accountability and Legitimacy. Nonprofit and Voluntary Sector Quarterly. 2020;49(1):93-112.

21. Kaltenbrunner K, Renzl B. Social Capital in Emerging Collaboration Between NPOs and Volunteers: Performance Effects and Sustainability Prospects in Disaster Relief. VOLUNTAS: International Journal of Voluntary and Nonprofit Organizations. 2019;30(5):976-990.

22. Aakko E, Weed N, Konrad R, Wiesman J. Rethinking Volunteer Management Using a Centralized Volunteer Staging and Training Area. Disaster Medicine and Public Health Preparedness. 2013;2(2):127-129.

23. Middleton G. Civilian Volunteers Building Public Health Resilience. Disaster Medicine and Public Health Preparedness. 2013;2(4):258-260.

24. Hasselmann AR. Successful Strategies for Recruitment of Emergency Medical Volunteers. Disaster Medicine and Public Health Preparedness. 2013;7(3):266-271.

25. Yafe E, Walker BB, Amram O, et al. Volunteer First Responders for Optimizing Management of Mass Casualty Incidents. Disaster Medicine and Public Health Preparedness. 2018;13(2):287-294.

26. Ganewatta G, Handmer J. The value of volunteers in State Emergency Services. Australian Journal of Emergency Management, The. 2009;24(2):26.

27. Bachner G, Seebauer S, Pfurtscheller C, Brucker A. Assessing the benefits of organized voluntary emergency services: Concepts and evidence from flood protection in Austria. Disaster Prevention and Management. 2016;25(3):298-313.

28. Sauer LM, Catlett C, Tosatto R, Kirsch TD. The Utility of and Risks Associated With the Use of Spontaneous Volunteers in Disaster Response: A Survey. Disaster Medicine and Public Health Preparedness. 2014;8(1):65-69.

29. Hodge JG, Pepe RP, Henning WH. Voluntarism in the Wake of Hurricane Katrina: The Uniform Emergency Volunteer Health Practitioners Act. Disaster Medicine and Public Health Preparedness. 2013;1(1):44-50.

30. Seddighi H, Salmani I, Seddighi H. Monetary value and cost analysis of a youth voluntary program on road safety in Iran. Journal of Injury and Violence Research. 2019;11(2).

31. Naini ARJ, Naderian MA. Oil price cycles, fiscal dominance and countercyclical monetary policy in Iran. OPEC Energy Review. 2019;43(1):3-28.

32. Langeberg M. Iran Workers' protests confront a regime in crisis. Green Left Weekly. 2019(1207):16.

33. IFRC. Youth VIVA Study. 2017; https://media.ifrc.org/ifrc/document/youth-viva-study/. Accessed 30/05, 2017.

34. Moghaddam SNM, Rafieian M. Urban development as a marionette? Oil income and urban development in post-revolutionary Iran. International Development Planning Review. 2020;42(2):191217.

35. Manetti G, Bellucci M, Como E, Bagnoli L. Investing in Volunteering: Measuring Social Returns of Volunteer Recruitment, Training and Management. VOLUNTAS: International Journal of Voluntary 
and Nonprofit Organizations. 2015;26(5):2104-2129.

36. Gouda P, Kirk A, Sweeney A-M, O’Donovan D. Attitudes of Medical Students Toward Volunteering in Emergency Situations. Disaster Medicine and Public Health Preparedness. 2019:1-4.

37. Breakout Session A: Extending Our Workforce Through Volunteers and Other Organizations. Disaster Medicine and Public Health Preparedness. 2014;8(6):571-572.

\section{Figures}

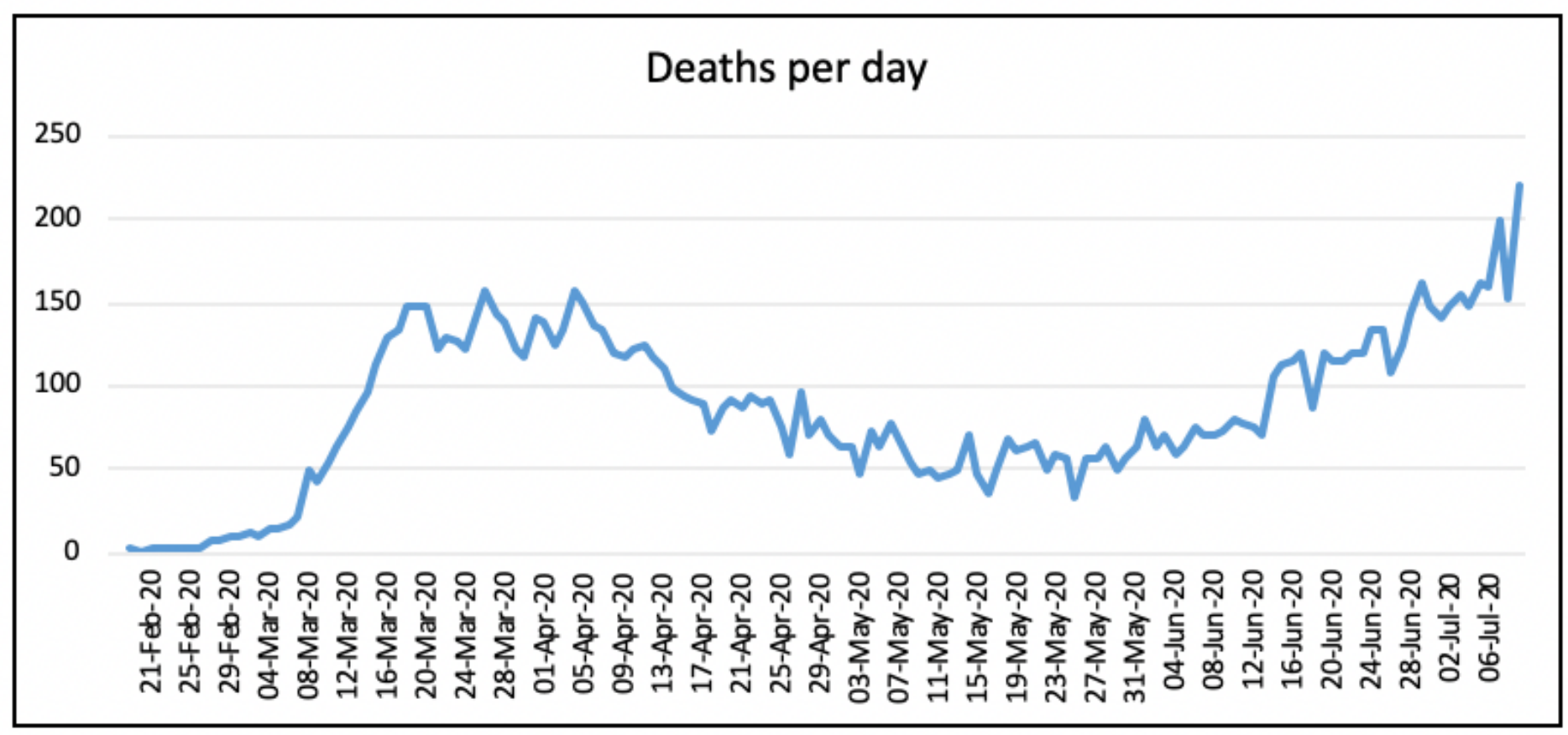

\section{Figure 1}

Number of death due to COVID-19 disease in Iran per day 